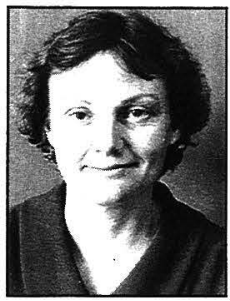

\title{
THE GROWTH OF EARNINGS \\ INEQUALITY, 1984-1997: \\ TRENDS AND SOURCES OF CHANGE
}

\author{
Sylvia Dixon \\ Labour Market Policy Group \\ Department of Labour
}

\begin{abstract}
Changes in the distribution of earnings in New Zealand between 1984 and 1997 are examined in this paper. There is evidence of growth in the inequality of both weekly and hourly earnings. Decomposition of the changes suggests that the increases in the dispersion of earnings were largely due to increased inequality within groups of workers with similar observed levels of education, age and potential work experience. ${ }^{1.2}$
\end{abstract}

Keywords: eamings, dispersion, inequality.

Changes in the distribution of earnings in New Zealand between 1984 and 1997 are examined in this paper. There is evidence of growth in the inequality of both weekly and hourly earnings. Decomposition of the changes suggests that the increases in the dispersion of earnings were largely due to increased inequality within groups of workers with similar observed levels of education, age and potential work experience.

The distribution of earnings is one of the foundations of the distribution of income. This paper provides an overview of some of the main changes in the distribution of earnings in New Zealand between 1984 and 1997, drawing on data from the Household Economic Survey (HES). There are several reasons for monitoring the distribution of earnings. Firstly, increases in the dispersion of wage rates or weekly earnings are likely to have flow-on consequences for total income inequality and for welfare, due to the fact that wages and salaries are the largest component of income for most individuals and households. Secondly, information about the changes in the distribution of earnings may contribute to a better understanding of other processes and trends in the labour market, such as shifts in the supply and demand for different types of skill. Thirdly, wide ranging economic and labour market reforms were implemented in New Zealand between 1984 and 1992. Those reforms were predicted to cause increased inequities in the labour market. It is interesting to assess whether the predicted increases in the inequality of earnings have actually occurred.

The paper begins by briefly noting the main findings of recent New Zealand research on the distribution of incomes. This is followed by a description of the data source used in this study. An overview of the main changes in the earnings distribution between 1984 and 1997 is then provided. The subsequent section analyses the relative contribution of three main sources of change in earnings inequality. Using a decomposition method developed by Juhn, Murphy and Pierce (1993), the total increase in earnings inequality over the 13-year period is decomposed into three components: shifts in the distribution of observed characteristics across the workforce; shifts in the wage differentials or 'returns' associated with those observed characteristics; and changes in unobserved factors. The final section of the paper discusses potential explanations for the growth of earnings inequality.

\section{Previous research}

There is a large body of international research on earnings inequality. This literature is reviewed in Levy and Murnane (1992), OECD (1993), OECD (1996) and Gottschalk and Smeeding (1997). Many (though not all) OECD countries experienced increases in earnings inequality during the 1980 's and 1990's. The size of those increases in inequality varied across countries and time periods, from small to substantial.

Several New Zealand researchers have looked at changes in the distribution of total annual incomes across households. Most have used the Household Economic Survey as their source. The earliest of these studies (New Zealand Planning Council, 1988 and 1990; Mowbray, 1993; and Mowbray and Dayal, 1994) found evidence of an increase in household income inequality between 1982 and 1993. An analysis of Population Census data by Martin (1997) also documented growth in the inequality of individual and household annual incomes between 1986 and 1996.

Two recent studies of income inequality (Podder and Chatterjee, 1998; and Statistics New Zealand, forthcoming) have looked specifically at trends in the dispersion of wage and salary incomes. Both used the HES as their data source and annual wage and salary income as their measure of earnings. Both studies found evidence of increases in the dispersion of earnings between the mid-1980s and the mid-1990's. 
The research undertaken previously by the author (1996a and 1996b), and the current study, differ from the other studies in analysing weekly and hourly rather than annual earnings. This alternative perspective is useful because some of the growth in annual earnings inequality could be caused by increasing variation among employees in the number of weeks worked per year. Measures of weekly and hourly earnings are less influenced by any changes that may have occurred in the stability of employment.

\section{Background information on the data}

\section{Data source and variable definitions}

The Household Economic Survey is a Statistics New Zealand survey of people living in private households. Income data, including details of all wages or salaries earned during the preceding 12 months, are collected from each adult in the survey. Each year, the HES collects data from around 7000 people, about 3,000 of whom have waged or salaried jobs at the time of the interview.

The current research utilises data on individuals' total pretax hourly and weekly earnings in their current wage and salary jobs (i.e. those held at the time of their interview). Overtime payments, allowances, bonuses and commissions are included in the earnings data presented in this paper.

Hourly earnings were estimated by dividing each individual's total weekly earnings by their usual total hours of work. It should be noted that hourly earnings estimated in this manner are not necessarily the same as negotiated hourly pay rates. For example, a person who regularly stays late at work, and includes unpaid as well as paid hours when reporting their usual weekly hours, may have average hourly earnings that are below their negotiated hourly pay rate.

The earnings data analysed in this paper are not adjusted for taxes or transfers, and therefore they do not measure changes in employees' average disposable earnings. Due to tax changes and the movement of people across income tax brackets, trends in the distribution of disposable earnings are likely to differ somewhat from trends in the distribution of gross earnings.

The years referred to in the tables and text are March years. For comparability over time, the nominal earnings data recorded by HES were deflated by the CPI to the equivalent of constant March 1994 dollars, using a CPI series that excludes the effects of the implementation of GST in the $1980 \mathrm{~s}^{3}$ Because HES interviewing and data collection are spread over the full calendar year, the data were also adjusted for the possible effects of variations in the timing of collection within years. Those "timing" adjustments were generally small and do not substantively affect either the data or the results of the research. ${ }^{4}$

\section{Data quality issues}

The quality of the HES data on earnings is limited in two respects. Firstly, due to the small size of the sample, sampling errors are relatively large, and survey estimates tend to be quite volatile from year to year. Estimates of sampling errors associated with the HES estimates are given in Dixon (1996a and forthcoming). Given these estimated sampling errors, most year-to-year movements in the various measures of earnings levels or earnings inequality are not statistically significant. However, the longer-term changes occurring over periods of 5 years or more are generally large enough to lie outside the relevant confidence intervals, and therefore can be regarded as meaningful changes.

Secondly, there are grounds for suspecting that some of the HES series may be affected by systematic measurement errors causing bias. Patterns visible in the HES hours of work data are suggestive of measurement error rising in magnitude over time. If these patterns do indeed represent measurement error, they have the potential to systematically distort the observed shape of the hourly earnings distribution and cause bias in summary measures of hourly earnings inequality, such as $90 / 10$ percentile ratios or Gini coefficients. ${ }^{5}$ In the absence of evidence on the true accuracy of the data obtained from field-based data validation studies, it is difficult to draw conclusions about the size or importance of this problem. However, it is important to be aware that the HES data analysed in this paper may give an imperfect picture of the true earnings distribution and the trends over time."

\section{Trends in the dispersion of earnings}

\section{Choice of inequality measures}

The distribution of earnings can be examined using hourly or weekly measures of earnings. Hourly earnings measures are often preferred because they correspond most closely to the concept of a "price" per unit of labour time (i.e., a wage rate). Weekly earnings can be affected by changes in the number of hours worked, as well as changes in wage rates or earnings per hour. This is true even if one excludes part-time workers when studying the weekly earnings distribution, which is the usual procedure.

Measurement error is also a consideration in the choice of a "preferred" earnings measure. There are grounds for suspecting that the HES hourly earnings estimates are of poorer quality than the weekly earnings estimates. Given this, it is advisable to consider the evidence offered by both the weekly and hourly series, rather than focusing primarily on hourly earnings.

There are numerous statistical measures of "inequality", and little consensus in the literature as to which measures should be given greatest weight. Percentile-ratio measures, such as the ratio of the 90th percentile of earnings to the 10 th, have the advantage that they are not influenced by observations at the upper and lower extremes of the earnings distribution, which are more likely to be measured with error. Three percentile-ratio measures of earnings dispersion are utilised here, along with the standard deviation of $\log$ earnings, the coefficient of variation of log earnings, and the Gini coefficient. 


\section{Summary measures of earnings inequality}

Figure 1 provides an initial visual summary of the way in which the distribution of earnings changed between 1984 and 1997. It simply graphs selected percentiles in the distribution of weekly earnings (full-time employees only), measured in constant (March 1994) dollars. The median of the distribution (i.e. the 50th percentile) moved up gradually over the period, from $\$ 515.20$ in 1984 to $\$ 567.22$ in 1997. The graph shows a gradual fanning out of the spread of the distribution, particularly at the upper end. For example, in 1984 the 90 th percentile $(\$ 877.34$ ) was 70 percent ( 1.70 times) higher than the 50th percentile. By 1997, the 90 th percentile ( $\$ 1084.32)$ was 91 percent (1.91 times) higher than the 50th percentile (\$567.22). Similarly, the 10 th percentile of the distribution $(\$ 303.27)$ represented 59 percent of the median in 1984 , falling to 56 percent of the median in 1997.

Figure 2 graphs a selection of percentile-based measures of dispersion in the weekly and hourly earnings of males and females. The lines on the graph represent the 90 th and the 10th percentiles of (weekly or hourly) earnings, expressed as a ratio of the median. Considering the distance of each line from the median line at the centre of the graph, it can be seen that the male earnings distributions - both weekly and hourly - are more dispersed than the female, particularly at the upper end. Figure 2 also shows a gradual fanning out of the spread of the distributions over time.

A more striking picture of the overall growth in earnings inequality is obtained by taking the end points of the series (1984 and 1997) and graphing the growth of earnings by percentile position in the distribution. Figure 3 shows the total change in log real weekly earnings over the 13-year period, by individuals' percentile in the earnings distribution. Employees who were at higher levels in the distribution experienced greater earnings growth, causing the lines on the graphs to be positively sloped. This was true for both males and females. A similar pattern of change emerges in Figure 4, which shows the total change in log hourly earnings by percentile position.

Numerical measures of the level and changes in earnings inequality are given in Table 1 . The first three inequality measures in each set of six are based on the distances between the 10th, 50th and 90th percentiles of log earnings. For example, the first row entries in columns (1) and (3) show that the gap between the 90 th and 10 th percentiles of the log weekly earnings of full-time employees rose from $106 \mathrm{log}$ points in 1984 to $123 \mathrm{log}$ points in 1997. The 'change' figures shown in columns (4) to (6) can be interpreted as approximate percentage changes. For example, the entries in the first row and columns (4) and (5) show that the log real weekly earnings gap between employees at the 90 th and 10th percentiles increased by around 5.4 percent between 1984 and 1990 , and by around 16.5 percent between 1990 and 1997. Estimates of the standard deviation of $\log$ earnings, the coefficient of variation of log earnings and the Gini coefficient of actual dollar earnings are also given for each earnings measure.

Several points can be made on the basis of Table 1. First, all measures of earnings indicate a rise in inequality between 1984 and 1997. Second, the increases in weekly earnings dispersion were generally larger than the increases in hourly earnings dispersion. This is a reflection of the fact that there were significant changes in the distribution of hours worked among wage and salary earners between 1984

\section{Figure 1. Percentiles of the weekly earnings distribution: all full-time employees}

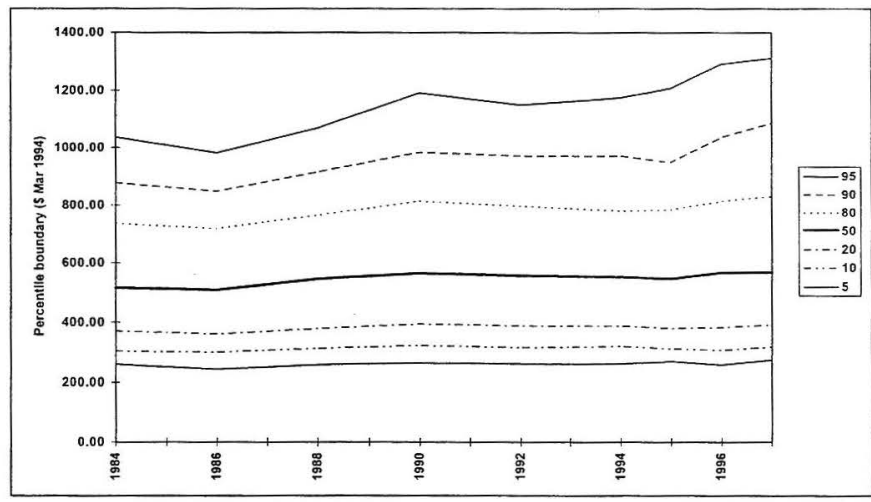


Figure 2. Trends in the dispersion of weekly and hourly earnings

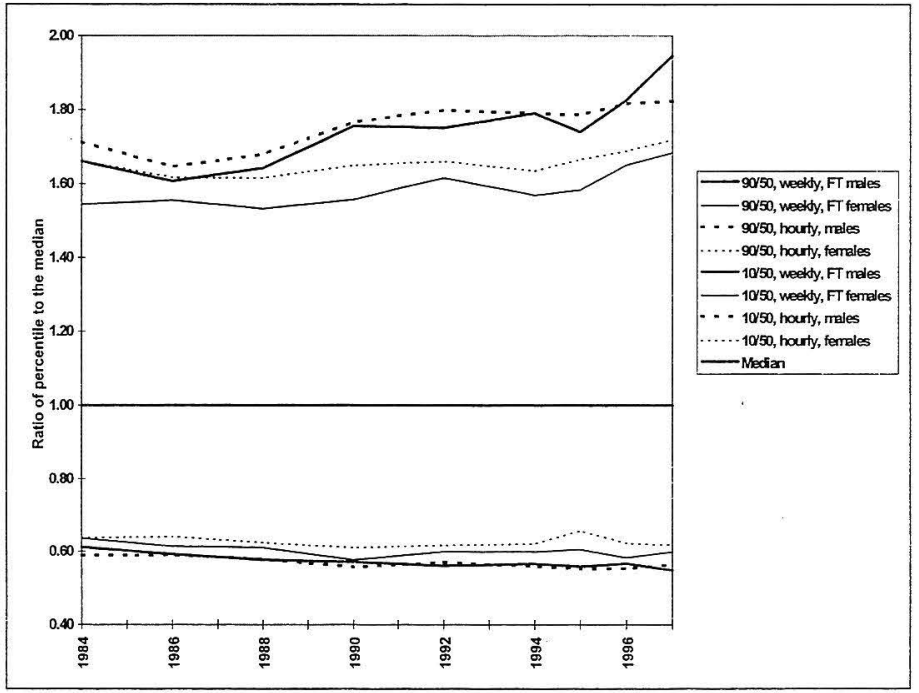

Figure 3. Changes in log real weekly earnings (full-time employees only) by percentile, 1984-97

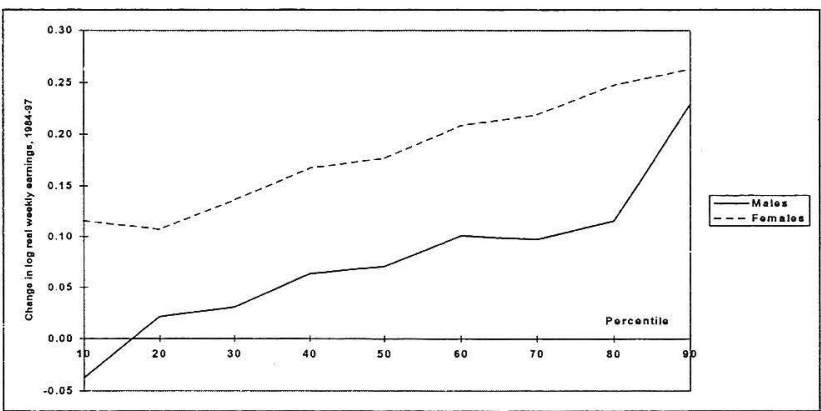


Figure 4. Changes in log real hourly earnings by percentile, 1984-97

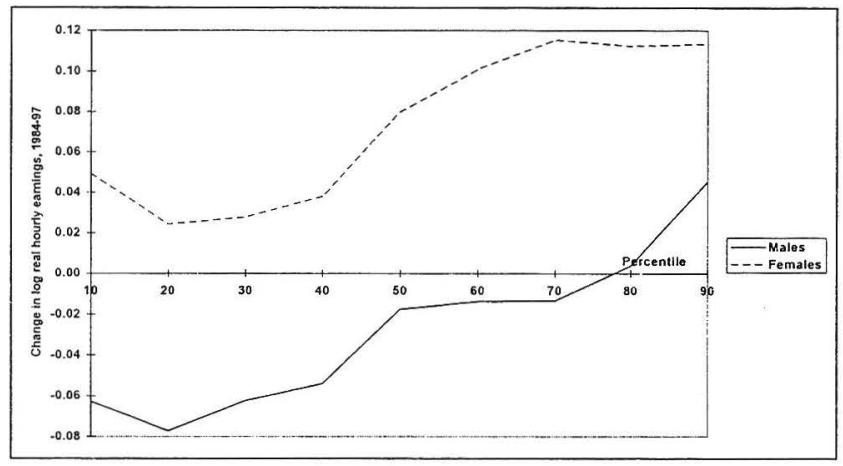

and 97 . The weekly hours worked (or reported) by higher paid workers increased on average, relative to the hours worked (or reported) by lower paid workers. This strengthening of the relationship between hours worked and level of earnings appears to have contributed to the total growth of weekly earnings inequality.

Third, the male weekly and hourly earnings distributions recorded greater rises in inequality than-the female earnings distributions. For example, the 90-10 log weekly earnings difference expanded by around $27 \log$ points ( 31 percent) for males and about $15 \mathrm{log}$ points ( 16 percent) for females over the total period.

Fourth, most measures suggest that inequality increased more rapidly between 1984 and 1990 than between 1990 and 1997. The measures of the growth in the dispersion of total and male weekly earnings between 1990 and 1997 are an exception to this pattern, as they show a big increase in inequality. However, the 90 th percentile estimate for male weekly earnings in 1997 appears to be outlier, giving a misleading picture of the total movement in dispersion between 1990 and 1997. The average annual increases in most inequality measures were generally smaller between 1990 and 1996 than those recorded in the earlier period, 1984 to 1990.

Finally, the growth of earnings dispersion was somewhat more pronounced in the upper half of the distribution than the lower half. This can be seen by comparing the movements in the 90-50 log differences with the movements in the 50-10 log differences. Taking male full-time log weekly earnings as an example, the $90-50$ percentile gap expanded by around 17 percent over the total period, while the 50-10 percentile gap increased by around 11 percent.
How reliable are these data on the long-term trends in earnings dispersion? Most year-to-year changes in the measures of dispersion reported in this paper lie within the approximate 95 percent confidence intervals that can be constructed using the standard errors of the estimates. In other words, they could readily be attributed to sampling variation. However, the longer-term shifts in the inequality indexes given in Table 1 (from 1984 to 1990, for example, or from 1990 to 1997) are generally large enough to lie well outside these confidence intervals, suggesting it is unlikely they are due to sampling variation alone.?

As noted earlier, it is possible that the inequality levels and trends apparent in the HES data are measured with some degree of bias, due to reporting or other non-random errors. Unfortunately, the presence of any such bias cannot be confirmed or rejected on the basis of the currently-available information about the quality of the survey data. It is worth bearing in mind, therefore, that the data analysed in this paper may give an imperfect picture of the true earnings distribution and the trends over time.

\section{Sources of the changes in earnings inequality}

The distribution of individual eamings can be changed by three basic processes (Borland, 1998, p.22):

(i) changes in the distribution of observed skill-related characteristics amongst employees in the workforce such as age, work experience, or qualifications;

(ii) changes in the wage differentials or "returns" that are paid in the labour market for the observed characteristics

(iii) changes in unobserved factors - that is, the changes in the distribution of earnings within groups of workers with the same observed characteristics. 
Table 1. Changes in the inequality of earnings, 1984-97

\begin{tabular}{|c|c|c|c|c|c|c|}
\hline Measure & $\begin{array}{r}1984 \\
(1) \\
\end{array}$ & $\begin{array}{r}1990 \\
(2) \\
\end{array}$ & $\begin{array}{r}1997 \\
(3) \\
\end{array}$ & $\begin{array}{r}\text { Chge } \\
1984-90 \\
(4) \\
\end{array}$ & $\begin{array}{r}\text { Chge } \\
1990-97 \\
(5) \\
\end{array}$ & $\begin{array}{r}\text { Chge } \\
1984-97 \\
(6) \\
\end{array}$ \\
\hline \multicolumn{7}{|l|}{$\begin{array}{l}\text { Weekly earnings } \\
\text { Full-time employees }\end{array}$} \\
\hline $90-10$ log difference & 1.06 & 1.12 & 1.23 & 0.054 & 0.110 & 0.165 \\
\hline $90-50$ & 0.53 & 0.55 & 0.65 & 0.023 & 0.093 & 0.116 \\
\hline $50-10$ & 0.53 & 0.56 & 0.58 & 0.031 & 0.018 & 0.049 \\
\hline Standard deviation of log & 0.43 & 0.48 & 0.52 & 0.041 & $0.04 \mathrm{I}$ & 0.082 \\
\hline Coefficient of variation & 0.45 & 0.53 & 0.62 & 0.074 & 0.090 & 0.165 \\
\hline Gini coeflicient & 0.23 & 0.26 & 0.28 & 0.024 & 0.021 & 0.045 \\
\hline \multicolumn{7}{|l|}{ Full-time males } \\
\hline $90-10 \log$ difference & 1.00 & 1.12 & 1.27 & 0.124 & 0.142 & 0.267 \\
\hline $90-50$ & 0.51 & 0.56 & 0.67 & 0.056 & 0.103 & 0.158 \\
\hline $50-10$ & 0.49 & 0.56 & 0.60 & 0.069 & 0.040 & 0.108 \\
\hline Standard deviation of $\log$ & 0.42 & 0.47 & 0.53 & 0.046 & 0.060 & 0.107 \\
\hline Coefficient of variation & 0.44 & 0.53 & 0.62 & 0.089 & 0.093 & 0.181 \\
\hline Gini coefficient & 0.23 & 0.26 & 0.29 & 0.031 & 0.030 & 0.061 \\
\hline \multicolumn{7}{|l|}{ Full-time females } \\
\hline $90-10$ log difference & 0.89 & 1.00 & 1.04 & 0.108 & 0.040 & 0.148 \\
\hline $90-50$ & 0.43 & 0.44 & 0.52 & 0.009 & 0.078 & 0.086 \\
\hline $50-10$ & 0.45 & 0.55 & 0.51 & 0.099 & -0.038 & 0.061 \\
\hline Standard deviation of $\log$ & 0.38 & 0.43 & 0.47 & 0.051 & 0.037 & 0.089 \\
\hline Coefficient of variation & 0.36 & 0.41 & 0.55 & 0.049 & 0.146 & 0.195 \\
\hline Gini coefficient & 0.19 & 0.22 & 0.24 & 0.022 & 0.025 & 0.047 \\
\hline \multicolumn{7}{|l|}{ Hourly earnings } \\
\hline \multicolumn{7}{|l|}{ All employees } \\
\hline $90-10 \log$ difference & 1.07 & 1.10 & 1.10 & 0.025 & 0.007 & 0.032 \\
\hline $90-50$ & 0.55 & 0.57 & 0.57 & 0.016 & 0.002 & 0.018 \\
\hline $50-10$ & 0.52 & 0.53 & 0.53 & 0.009 & 0.004 & 0.014 \\
\hline Standard deviation of log & 0.45 & 0.48 & 0.49 & 0.026 & 0.014 & 0.040 \\
\hline Coeflicient of variation & 0.47 & 0.55 & 0.58 & 0.074 & 0.032 & 0.105 \\
\hline Gini coefficient & 0.24 & 0.26 & 0.27 & 0.022 & 0.007 & 0.028 \\
\hline \multicolumn{7}{|l|}{ Males } \\
\hline $90-10 \log$ difference & 1.07 & 1.16 & 1.18 & 0.091 & 0.019 & 0.110 \\
\hline $90-50$ & 0.54 & 0.57 & 0.60 & 0.031 & 0.031 & 0.062 \\
\hline $50-10$ & 0.53 & 0.59 & 0.58 & 0.060 & -0.012 & 0.047 \\
\hline Standard deviation of log & 0.46 & 0.50 & 0.52 & 0.038 & 0.019 & 0.057 \\
\hline Coefficient of variation & 0.47 & 0.53 & 0.60 & 0.068 & 0.064 & 0.132 \\
\hline Gini coefficient & 0.24 & 0.27 & 0.28 & 0.026 & 0.015 & 0.041 \\
\hline \multicolumn{7}{|l|}{ Females } \\
\hline 90-10) log difference & 0.96 & 0.99 & 1.02 & 0.031 & 0.031 & 0.063 \\
\hline $90-50$ & 0.51 & 0.50 & 0.54 & -0.010 & 0.044 & 0.034 \\
\hline $50-10$ & 0.45 & 0.49 & 0.48 & 0.041 & -0.013 & 0.029 \\
\hline Standard deviation of log & 0.41 & 0.43 & 0.45 & 0.026 & 0.020 & 0.046 \\
\hline Coefficient of variation & 0.43 & 0.54 & 0.53 & 0.107 & -0.010 & 0.097 \\
\hline Gini coefficient & 0.22 & 0.24 & 0.24 & 0.025 & 0.004 & 0.030 \\
\hline
\end{tabular}

$90-50=$ the difference between the 90 th percentile of log earnings and the median.

The other percentile ratios are similarly defined.

All measures except the Coefficient of Variation and the Gini coefricient are calculated on log earnings. 
This section of the paper examines the relative size and relative importance of these three components of the total rise in earnings inequality - using a method of decomposition developed by Juhn, Murphy and Pierce (1993).

The set of individual characteristics that can be observed through the HES includes gender, age, estimated potential work experience (age minus estimated years of schooling), educational qualifications, and ethnic identity. Hours of work, industry and occupation are also observable and could potentially be used as predictors of earnings. In this analysis, I use the available information on demographic and socio-economic characteristics and hours worked, but exclude industry and occupation. ${ }^{*}$

\section{Table 2. Changes in employment shares of the main population groups}

(from HES sample of employees)

\begin{tabular}{|c|c|c|c|}
\hline & $\begin{array}{c}\text { \% share } \\
1984 \\
\end{array}$ & $\begin{array}{c}\text { \% share } \\
1997\end{array}$ & $\begin{array}{l}\text { change } \\
1984-97\end{array}$ \\
\hline Males & 57.6 & 52.0 & -5.6 \\
\hline Females & 42.4 & 48.0 & 5.6 \\
\hline $15-24$ & 27.4 & 19.5 & -7.9 \\
\hline $25-54$ & 63.4 & 71.1 & 7.7 \\
\hline $55 \div$ & 9.2 & 9.5 & 0.3 \\
\hline Pakeha & 88.4 & 82.6 & -5.8 \\
\hline Maori & 7.8 & 8.5 & 0.7 \\
\hline Other ethnicity & 3.8 & 8.9 & 5.1 \\
\hline No qualifications & 40.0 & 21.5 & -18.5 \\
\hline School quals only & 25.1 & 34.0 & 8.9 \\
\hline Trade, other tertiary & 25.3 & 27.4 & 2.1 \\
\hline University quals & 9.5 & 15.2 & 5.7 \\
\hline Full-time & 80.2 & 76.0 & -4.2 \\
\hline Part-time & 19.8 & 24.0 & 4.2 \\
\hline
\end{tabular}

The role played by educational qualifications age and/or work experience is of particular interest in the analysis of inequality trends because these characteristics are the best observed indicators of "skill". A key question for educational and labour market policy is whether the growth of inequality was driven by increases in the relative demand for workers with higher levels of "skill". By examining the effects of changes in the distribution of education and age/ experience, and the effects of changes in the returns to education and age/experience, it is possible to go some way towards answering this question.

\section{Changes in observed characteristics and returns}

Before undertaking the decomposition, it is worth briefly reviewing the direct evidence on the main changes in the distribution of observed characteristics and returns. ${ }^{9}$

Between 1984 and 1997, there were substantial shifts in the composition of the labour force, causing change in the distribution of observed characteristics within the population of wage and salary earners. Information on the changes in the composition of the HES samples is presented in Table 2. Between 1984 and 1997, females, prime-aged workers, non-Pakeha, and workers with school or post-school qualifications increased their relative employment shares. The employment shares of males, young people, Pakeha, and workers without any formal qualifications declined. Most notably, the proportion of workers who were aged 15-24 years fell from 27.4 percent to 19.5 percent, and the proportion without any formal qualifications fell from 40.0 percent to 21.5 percent.

These changes were large enough to have had some direct impacts on the dispersion of earnings, potentially at least. For example, the decline in the employment share of 15-24 year olds, a group with relatively low earnings, might be expected to push up the relative position of the lowest percentiles of the distribution and raise mean and median earnings, all other things being equal. The rise in the share of female employment might tend to reduce the growth of total earnings dispersion, because of the fact that female earnings are less dispersed than male. In practice, these tendencies may have been offset by other factors. The decomposition technique used in the next section provides a way of estimating the net impact of the compositional changes in the labour force.

A simple wage regression can be used to identify changes over time in the wage differentials or 'returns' that are associated with observed characteristics. The following wage equation was estimated separately for each year:

Log real hourly earnings $=\mathrm{f}$ (gender, age, age squared, education, ethnicity, part-time status)

Age and age squared are measured in years, while the other independent variables are represented by dummies. There are 3 dummy variables for educational level, two for ethnicity, and 1 for part-time status. Together, the binary variables in the model estimate variations in average earnings in comparison to the excluded group of male, full-time, Pakeha earners with school qualifications. ${ }^{10}$

Results for the years 1984, 1990 and 1997 are given in Table 3 . The coefficients for each attribute can be interpreted as estimates of the average premium (or deficit) that is paid for that particular characteristic. For example, the entry for 'female' in 1984 indicates that the predicted earnings of females were $16.2 \log$ points, or about 15 percent, below the predicted earnings of males after differences in other basic characteristics are controlled for. 
Table 3. Regression of individual characteristics on log hourly earnings

\begin{tabular}{lccc}
\hline & 1984 & 1990 & 1997 \\
\hline Coefficients & & & \\
Intercept & $1.471^{*}$ & $1.301^{*}$ & $1.226^{*}$ \\
Female & $-0.162^{*}$ & $-0.146^{*}$ & $-0.093^{*}$ \\
Age & $0.062^{*}$ & $0.067^{*}$ & $0.065^{*}$ \\
Age ${ }^{2}$ x 1000 & $-0.692^{*}$ & $-0.751^{*}$ & $-0.724^{*}$ \\
No qualification & $-0.154^{*}$ & $-0.181^{*}$ & $-0.198^{*}$ \\
Vocational qualification & 0.056 & $0.114^{*}$ & $0.086^{*}$ \\
University qualification & $0.257^{*}$ & $0.344^{*}$ & $0.263^{*}$ \\
Maori & -0.032 & -0.018 & -0.038 \\
Other non-Pakeha-ethnicity & -0.022 & -0.061 & $-0.109^{*}$ \\
Part-time worker & $-0.117^{*}$ & $-0.095^{*}$ & -0.119 \\
& & & \\
F & 182 & 135 & 112 \\
Adj R $\mathbf{R}^{2}$ & 0.313 & 0.304 & 0.270 \\
Sample size & 3,981 & 3,372 & 3,001 \\
\hline
\end{tabular}

* Denotes statistically significant at the $5 \%$ error level

Few of the coefficients were moving consistently in a direction that would cause increased total inequality. The coefficients for 'female', which are negative in sign, decline in size from 1984 to 1997. This indicates that the earnings 'deficit' associated with being female was becoming smaller, contributing to a reduction in total earnings inequality. The coefficients for age and age squared display relatively little change over time." The coefficients for "no qualification' are negative and rising in size, suggesting that the penalty in the labour market for having no formal qualifications may have become larger. The coefficients for vocational and university qualifications increased between 1984 and 1990, but declined in size between 1990 and 1997 - which is not consistent with the idea of a consistent trend towards higher earnings premia for post-school qualifications. ${ }^{12}$ Most of the ethnic group coefficients are not statistically significant.

Overall, this direct evidence on the earnings differentials associated with the primary set of observed skill-related characteristics suggests that few of those differentials were moving consistently in a direction that would cause increased total inequality.

\section{Decomposition of the sources of change in inequality}

Juhn, Murphy and Pierce (1993) have developed a method for decomposing changes in earnings inequality between: (i) the effects of change in the distribution of employees' observed skills; (ii) changes in the returns to those observed skills; and (iii) other 'unexplained' factors. For space reasons, the method is not explained here: an account is given in Dixon (forthcoming).

In this study, the decomposition was applied separately to the weekly earnings of full-time employed males and females who were aged 20 years or over. ${ }^{13}$ The variables used in the underlying regressions to predict the 'observed' component of the variation in earnings were age and age squared, educational qualifications, a complete set of interactions between age, age squared and qualifications, three ethnic group dummies, and log weekly hours worked. The impact of growth over time in the level of real earnings was removed from the decomposition.

Results are shown in Tables 4 and 5. Entries in the first column of Table 4 give percentile difference and standard deviation measures of the total change in log weekly earnings inequality between 1984 and 1997. Entries in the next three columns represent the three components of change, and sum to the total. The figures in the column (2) show the net effects of changes in the distribution of observed individual characteristics. Those effects are small relative to the total change in inequality, and some of the figures for males are negative in sign, implying reduced inequality. Figures in the third column show the effects of changes in earnings premia for observed characteristics. Those effects are generally positive in sign, and are somewhat larger than the compositional effects in the case of males, but smaller in the case of females. The effects of changes in the unobserved factors are shown in column (4). These entries represent the largest component of change (as shown in the final column of the table, giving the ratio of (4) to (1). An interpretation of these results is that increases in earnings inequality within groups of workers with the same observed characteristics made the largest contribution to the total rise in earnings dispersion. ${ }^{14}$

One concern about the results shown in Table 4 is that they might be strongly influenced by changes in the distribution of hours worked. To address this concern, the estimates presented in Table 5 focus on the effects of changes in age and education alone. In the regressions underlying these results, the distributions and the returns to age and education were allowed to vary from year to year, while other observed characteristics (ethnicity and hours worked) were held constant at their mean levels. Results are given for the sub-periods 19841990 and 1990-97, as well as for 1984-97.

Changes in the distribution of age and education (shown in the first three columns) generally had small net effects sometimes positive, sometimes negative - in all periods and for both males or females. Changes in the returns to age and education contributed to increases in the inequality of male earnings in the $1984-90$ period. Between 1990 and 1997, in contrast, the effects were negative. For females, the effects of changes in the returns to age and education were positive in both periods. The net contribution of both the changes in age and educational composition, and the changes in the coefficients for age and education, to the total increase in inequality, is estimated in the final column and was possibly in the range of 5-20 percent. Comparison of the 90-50 and 50-10 differentials suggests that the age and education effects may have been larger at the lower end of the distribution than at the upper end (which is consistent with the evidence in Table 3 of an increased negative earnings differential for 'no qualifications'). 
Table 4. Decomposition of the change in dispersion of $\log$ full-time weekly earnings, 1984-97

\begin{tabular}{|c|c|c|c|c|c|}
\hline & $\begin{array}{r}\text { Total change } \\
\text { (1) }\end{array}$ & $\begin{array}{r}\text { Change in } \\
\text { observed } \\
\text { characteristics } \\
(2)\end{array}$ & 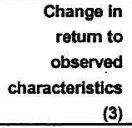 & $\begin{array}{r}\text { Change in } \\
\text { unobserved } \\
\text { factors } \\
(4)\end{array}$ & $\begin{array}{r}\text { Relative } \\
\text { contribution of } \\
\text { unobserved } \\
\text { factors } \\
(4 / 1) \\
\end{array}$ \\
\hline \multicolumn{6}{|l|}{ Males } \\
\hline \multicolumn{6}{|l|}{ Percentile differences } \\
\hline $90-10$ & 0.246 & 0.040 & 0.076 & 0.131 & 0.531 \\
\hline $90-50$ & 0.164 & 0.044 & 0.031 & 0.089 & 0.544 \\
\hline $50-10$ & 0.082 & -0.004 & 0.044 & 0.041 & 0.506 \\
\hline Standard deviation & 0.129 & 0.012 & 0.025 & 0.091 & 0.708 \\
\hline \multicolumn{6}{|l|}{ Females } \\
\hline \multicolumn{6}{|l|}{ Percentile differences } \\
\hline $90-10$ & 0.184 & 0.068 & -0.021 & 0.138 & 0.747 \\
\hline $90-50$ & 0.064 & 0.019 & -0.035 & 0.080 & 1.251 \\
\hline $50-10$ & 0.120 & 0.049 & 0.014 & 0.058 & 0.480 \\
\hline Standard deviation & 0.099 & 0.027 & 0.000 & 0.073 & 0.733 \\
\hline
\end{tabular}

Table 5. Contribution of age and education to the change in the distribution of $\log$ full-time weekly earnings, 1984-97

\begin{tabular}{|c|c|c|c|c|c|c|c|}
\hline & \multicolumn{3}{|c|}{$\begin{array}{c}\text { Changes in distribution } \\
\text { of age \& education }\end{array}$} & \multicolumn{2}{|c|}{$\begin{array}{l}\text { Changes in returns to } \\
\text { age \& education }\end{array}$} & \multirow{2}{*}{\multicolumn{2}{|c|}{$\begin{array}{rr}\begin{array}{r}\text { Relative } \\
\text { contribution } \\
\text { of age \& educ }\end{array} \\
\text { 1984-97 } & 1984-97\end{array}$}} \\
\hline & $1984-90$ & $1990-97$ & $1984-97$ & $1984-90$ & $1990-97$ & & \\
\hline \multicolumn{8}{|l|}{ Males } \\
\hline \multicolumn{8}{|l|}{ Percentile differences } \\
\hline $90-10$ & -0.014 & 0.024 & 0.010 & 0.045 & -0.020 & 0.024 & 0.140 \\
\hline $90-50$ & -0.037 & 0.029 & -0.007 & 0.022 & -0.010 & 0.012 & 0.030 \\
\hline $50-10$ & 0.022 & -0.005 & 0.017 & 0.023 & -0.011 & 0.012 & 0.361 \\
\hline Standard deviation & 0.000 & 0.006 & 0.006 & 0.014 & 0.001 & 0.015 & 0.164 \\
\hline \multicolumn{8}{|l|}{ Females } \\
\hline \multicolumn{8}{|l|}{ Percentile differences } \\
\hline $90-10$ & -0.034 & 0.021 & -0.013 & 0.007 & 0.009 & 0.015 & 0.014 \\
\hline $90-50$ & -0.057 & 0.004 & -0.053 & -0.018 & 0.008 & -0.010 & -0.984 \\
\hline $50-10$ & 0.023 & 0.016 & 0.040 & 0.024 & 0.001 & 0.025 & 0.543 \\
\hline Standard deviation & -0.003 & 0.085 & 0.083 & 0.006 & -0.080 & -0.074 & 0.093 \\
\hline
\end{tabular}

To summarise these results, the largest portion of the growth in inequality between 1984 and 1997 occured within groups of workers with similar observed individual characteristics. Changes in the returns to age and education made a smaller but generally positive net contribution to the growth in inequality (with the exception of male earnings during the 1990's, for which the contribution was negative) Changes in the distribution of observed characteristics within the population of wage and salary earners did not have very large net effects, either positive or negative.

\section{Explaining the rise in inequality - further research}

The finding that unobserved factors, causing increased inequality within groups of workers with similar observed characteristics, made the largest contribution to the total growth of earnings inequality in New Zealand, parallels findings reported for other OECD countries. For example,
Borland and Kennedy (1998) conclude that changes in unobserved determinants of inequality were the dominant factor behind the growth of earnings dispersion in Australia between 1982 and 1994-95. In this section I briefly discuss the range of possible explanations for rising within-group inequality, drawing on the overseas literature.

Much of the literature has focused on factors that may have led to changes in the distribution of unobserved 'skills', or changes in the returns to those unobserved skills. Unobserved skills might include individual characteristics such as intelligence, problem-solving ability, communication skills, or motivation and perseverance. Unobserved skills might also include elements of formal skills that are not captured by the data (e.g. the quality of a qualification, or subject area). Industry or firm-specific skills might also function as unobserved skills that influence the distribution of earnings, particularly if labour market adjustment is slow. 
Examples of supply-side factors that might lead to changes in the distribution of unmeasured skills include a decline in the quality of educational qualifications, or an increase in the share of immigrants in the population. New Zealand experienced an unusually large inflow of immigrants from non-English speaking background countries in the first half of the 1990's, suggesting that immigration is a potential candidate for further investigation. While it seems very likely that immigrants differ from New Zealand-born residents in their unobserved skills, it seems less likely that immigrant numbers were large enough to cause material changes in the aggregate wage structure.

On the labour demand side, there are a range of factors that might lead to change either the distribution of unmeasured skills (through their impacts on the level and composition of employment) or the prices for unmeasured skills. These include technological change; import penetration; changes in the industry composition of employment driven by shifts in product demand patterns; and business cycles. The influence of some of these factors will be difficult to investigate in the New Zealand context, given the lack of disaggregated time series statistics on capital stocks or technology. However, using Population Census data (with income as a proxy measure of earnings) it should be possible to investigate the relationship between changes in the industrial and occupational composition of employment and changes in inequality, at regional as well as national levels. This would improve our capacity to discriminate between alternative hypotheses regarding the underlying forces of change, such as import competition, or technology.

Some other explanations for rising inequality proposed in the literature are 'non-competitive' in the sense that they assume the persistence of some systematic divergence between individuals' wages and the marginal product of their labour. One hypothesis is that increases in the dispersion of industry or firm-specific earnings premia have contributed to the rise in total earnings inequality. Those industry or firm-specific earnings premia do not reflect differences in the skill profile of employees or the disutility of work, but instead represent rents: worker shares in excess profits. Another hypothesis is that changes in labour market institutions, such as the decentralisation of wage-setting decisions, or the decline in the involvement of unions in wage setting, have caused the increases in the dispersion of earnings. None of these explanations will be easy to explore in the New Zealand context, given the lack of firm-level data sets, reliable measures of union membership, or surveybased industrial relations data. Nevertheless, there may be some scope for further research on these topics.

\section{Conclusion}

Between 1984 and 1997, New Zealand experienced increases in weekly and hourly earnings inequality, especially among males. Both weekly and hourly earnings dispersion were substantially higher among male employees in 1997 than was the case in 1984. Female earnings dispersion also rose, although the increases for females were somewhat smaller. Much of the growth in inequality occurred in the
1984-1990 and 1995-97 periods; the pace of growth was slower between 1990 and 1995 . The evidence that inequality was rising before 1991, and did not pick up noticeably in pace after 1991, does not seem to provide direct support for the notion that the Employment Contracts Act (1991) made a fundamental difference to the growth of earnings inequality in New Zealand.

Changes in earnings differentials associated with measured skill-related characteristics, such as formal qualifications, age and potential years of work experience, made a positive net contribution to the total rise in earnings inequality, particularly during the 1980 's. However, most of the growth in inequality occurred within the main demographic and skill groups and was caused by unobserved factors.

\section{Future research}

Future researchers should consider using the HLFS Income Supplement as their data source, as an alternative and richer data source than the HES. Further assessment of the effects of supply and demand shifts on educational earnings differentials could be undertaken. The relationship between changes in the industrial and occupational structure of employment and changes in income inequality at the regional or area level could be investigated using census data. This might shed some light on the impacts of exogenous factors such as import competition or technological change.

\section{Notes}

1 Access to the data used in this study was provided by Statistics New Zealand under conditions designed to give effect to the confidentiality provisions of the Statistics Act 1975. The results presented in this paper are not the work of Statistics New Zealand.

2 The assistance of Dave Maré, Simon Chapple and three anonymous referees who provided comments on a previous draft paper, is gratefully acknowledged. The views expressed in this paper are not necessarily those of the Department of Labour.

3 The GST-adjusted CPI series calculated by the RBNZ was used for this purpose. Roger (1995) outlines the methods used to calculate this series.

4 Further information on the HES data and data adjustments is given in Dixon (1996a, and forthcoming).

5 The issue of systematic measurement error, and the evidence suggesting that it may be affecting the data used in this study, is considered in Dixon (forthcoming).

6 A new data source on the distribution of earnings has been developed by Statistics New Zealand - the Household Labour Force Survey Income Supplement. This annual survey was collected for the first time in June 1997. Currently, there are insufficient observations for time series analysis. In the long-run, however, the HLFS Income Supplement may yield more reliable information on changes in the earnings distribution than does the HES.

7 The main exception to this generalisation is the shifts 
in the positions of the 90 th and 10 th percentiles of hourly earnings between 1990 to 1997, which are relatively small. Those movements lie inside the estimated confidence intervals.

8 Industry and occupation were excluded so that the results would be more comparable with those typically reported in the overseas literature.

9 A more detailed analysis of the changes that have occurred in the distribution of observed earnings-related characteristics and the 'returns' to those characteristics is given in Dixon (forthcoming).

10 Gender, age, ethnicity and qualifications are standard human capital variables. The variables age and age squared were included to control for the non-linear effect of work experience, which is expected to increase with age. A dummy for part-time status was included to capture any differences between the earnings functions of part-time and full-time employees, arising from differences in unmeasured dimensions of productivity (such as firm-specific training) or from differences in the way in which measured attributes such as age and qualifications are rewarded.

11 Other more detailed regressions (not reported here) show evidence of a decline in the relative earnings of 15-24 year olds - but little change in the relationship between age and earnings elsewhere in the age structure. Earnings differentials associated with years of potential work experience were also examined. Those differentials did not show a clear upward or downward trend over time.

12 Age and age squared were interacted with each qualification level in a separate regression. The age-specific educational differentials estimated from this equation also show little sign of growth during the 1990's.

13 The full-time weekly earnings measure and the restriction of the population to mature workers were chosen to make the results comparable with those reported elsewhere, eg. Borland (1998).

14 If information on occupation and industry was included, the 'unexplained' components of change would probably become smaller.

\section{References}

Borland, J. (1998) Earnings inequality in Australia: Changes, causes and consequences. Centre for Economic Policy Research Discussion Paper No. 390.

Borland, J. and Kennedy, S. (1998) Earnings inequality in Australia in the 1980 s and 1990s. Centre for Economic Policy Research Discussion Paper No. 389.

Dixon, S. (1996a) The distribution of earnings in New Zealand 1984-94. Labour Market Bulletin 1996:1: 45 100

Dixon, S. (1996b) The distribution of earnings in New
Zealand 1984-95. In Morrison, P. S. (ed.) Proceedings of the Seventh Labour, Employment and Work Conference, 28-29 November 1996, Victoria University of Wellington. 31-42

Dixon, S. (1988) Growth in the dispersion of earnings: 1984-97. Labour Market Bulletin, 1998:1.

Gottschalk, P. and Smeeding T. (1997) Cross-national comparisons of earnings and income inequality. Journal of Economic Literature, 35 (2): 633-87.

Juhn, C., Murphy, K. and Pierce, B. (1993) Wage inequality and the rise in returns to skill. Journal of Political Economy, 101(3): 410-42.

Levy, F. and Murnane, R. (1992) US earnings levels and earnings inequality: A review of recent trends and proposed explanations, Journal of Economic Literature, $30(3)$ : 1333-81

Martin, B. (1997) Income Trends among Individuals and Families, 1976 to 1996. Briefing paper prepared for the Population Conference, Wellington 12-14 November 1997. Population Studies Centre, University of Waikato.

Mowbray, M. (1993) Incomes Monitoring Report, 198191. Social Policy Agency, Wellington.

Mowbray, M. and Dayal, N. (1994) The fall and rise (??) of household incomes. Social Policy Joumal of New Zealand. 2:114-22.

New Zealand Planning Council (1988) For richer for poorer: Income and wealth in New Zealand. Wellington, NZPC.

New Zealand Planning Council (1990) Who gets what? The distribution of income and wealth in New Zealand. Wellington, NZPC.

OECD (1993) Eamings inequality: changes in the 1980's. OECD Employment Outlook, July 1993: 157-84.

OECD (1996) Earnings inequality, low-paid employment and earnings mobility. OECD Employment Outlook, July 1996: 59-108.

Podder, N. and Chatterjee, S. (1998) Sharing the national cake in post-reform New Zealand: Income inequality trends in terms of income sources. Unpublished paper presented the New Zealand Association of Economists' Conference, Wellington, 2-4 September 1998.

Roger, S. (1995) The GST shocks: revisited and revised. Reserve Bank research memorandum \#M95/45.

Statistics New Zealand (1999) Incomes. Wellington, Statistics New Zealand : 1981 to 1996.

\section{Author}

Sylvia Dixon is an Economic Analyst in the Labour Market Policy Group, Department of Labour, PO Box 3705, Wellington.

E-mail: sylvia.dixon@lmpg.dol.govt.nz 